\title{
Solvatochromic Fluorescence Behavior of 8-Aminoquinoline-Benzothiazole: A Sensitive Probe for Water Composition in Binary Aqueous Solutions
}

\author{
Young-Hee Kim, Jin-Soo Youk, So Hee Kim, and Suk-Kyu Chang* \\ Department of Chemistry, Chung-Ang University, Seoul 156-756, Korea. 'E-mail: skchangacan.ack kr \\ Recened August 10, 2004
}

\begin{abstract}
Solvatochromic fluorescence behavior of 8 -aminoquinoline based benzothiazole derivative in varying solvent systems has been investigated. Benzothiazole appended 8-aminoquinoline $\mathbf{3}$ showed distinctive fluorescence color changes depending upon the solvent polarities and the fluorescence color changes occurred over relatively wide span in visible region from $486 \mathrm{~nm}$ to $598 \mathrm{~nm}$ which can be detected with naked eye. Compound 3 also exhibited significant spectral shifts in $\lambda_{c t l}$ as a function of water composition in binary aqueous solvent systems. The changes are due to the specific interaction of 3 by hydrogen bonding with water as well as general solvent effect. The observed solvatochromic fluorescence characteristics of $\mathbf{3}$ could be used as a new probe for the micro-environmental polarity changes as well as a sensitive sensor for the determination of water composition in binary aqueous solutions.
\end{abstract}

Key Words : Fluorescence solvatochromism, 8-Aminoquinoline, Solvent polarity, Water composition, Binary aqueous solution

\section{Introduction}

In recent years considerable efforts have been given to the design and synthesis of functional molecules that could serve as sensitive sensors for the analytical detection of chemically and biologically important ionic species.' For this purpose, the advantages of fluorescence signaling in high selectivity and sensitivity have encouraged the development of a variety of interesting and practically usable fluorescence probes. ${ }^{2}$ Along with intense research efforts for the development of sensors towards ionic species, solvatochromic or solvatofluorochromic methods for the characterization of micro-environment polarity have also been attracted much interest. ${ }^{3.5}$ The polarity concept can be applied for the analysis of the nature of important local sites in many of macromolecular systems including synthetic polymers. ${ }^{6}$ proteins. ${ }^{7}$ and nucleic acids. ${ }^{8}$ On the other hand. application of solvatochromic methods to mixed solvent systems, especially to mixed aqueous solutions, ${ }^{9.10}$ is particularly more useful since aqueous solvent systems are widely used in reverse phase liquid chromatography and capillary electrophoresis."

A large number of quinoline derivatives have been synthesized continually because the quinoline moiety has welldefined and attractive ionophoric properties toward a variety of important metal ions. ${ }^{12}$ We have reported that the 8 aminoquinoline derivative 3 having appended benzothiazole function has $\mathrm{Hg}^{2-}$-selective fluoroionophoric behavior. ${ }^{13}$ During the search for the optimized condition of the $\mathrm{Hg}^{2+}$ selective fluorogenic behavior of $\mathbf{3}$ we have observed a significant dependence of fluorescence behavior upon the polarity of the employed solvents. In this paper, we report that the 8-aminoquinoline derivative having appended benzothiazole function has pronounced solvatochromic fluorescence behavior in aqueous solvent systems. The compound can be used as a sensitive probe for measuring polarity of the micro-environments in chemical and biological systems as well as for the assessment of the water composition in binary aqueous solutions.

\section{Results and Discussion}

The desired compound, benzothiazole derivative of 8 aminoquinoline 3, was synthesized in three steps ${ }^{14-16}$ from 8 nitro-2-methylquinoline as preliminarily reported earlier (Scheme 1). . $^{13}$

Preliminary absorption properties of 3 were investigated by UV-Vis spectroscopy. In acetonitrile solution, compound $\mathbf{3}\left(2.0 \times 10^{-5} \mathrm{M}\right)$ showed an intense absorption band $\left(\hat{\lambda}_{\text {нихx }}\right)$ at $310 \mathrm{~nm}$. The absorption spectra of $\mathbf{3}$ in other solvents of varying polarity were similar in appearance with no appreciable characteristic changes. On the other hand, the ionophore $3\left(2.0 \times 10^{-5} \mathrm{M}\right)$ showed an intense bright yellow fluorescence around $580 \mathrm{~nm}\left(\lambda_{\mathrm{xx}}=310 \mathrm{~nm}\right)$ in acetonitrile and significant changes in fluorescence spectra were observed in varying solvent systems. Therefore, we have measured fluorescence spectra of 3 in a variety of common organic

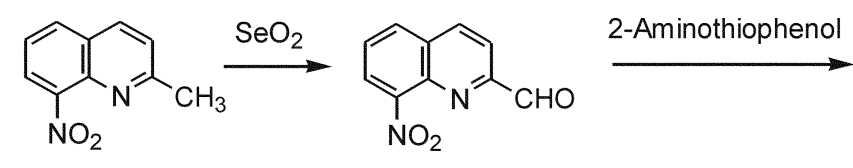

1

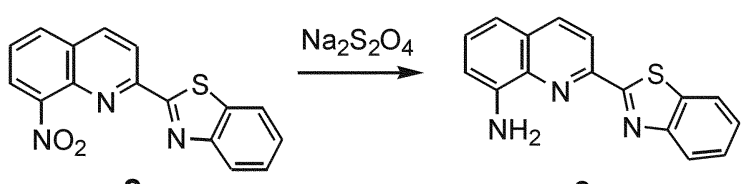

2

3

Scheme 1 


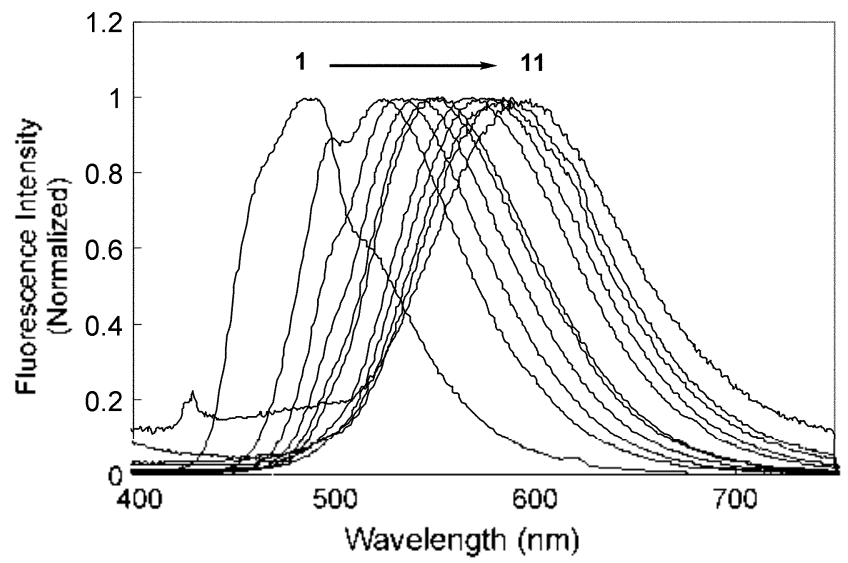

Figure 1. Normalized lluorescence spectra of 3 in varying solvents. Solvents: from left to right. 1, hexanc: 2 . toluene: 3 . ethyl sther; 4 . dioxane: 5 , ethy] acetate; 6 , THF: 7 , acetone: 8 , acetonitrile; $9, n$ propanol: 10, ethanol: 11. methanol.

solvents including some of their aqueous solutions. Compound 3 revealed a significant dependence of fluorescence spectral behavior upon the solvent employed and, in general, the fluorescence maximum $\lambda_{\text {enl }}$ of $\mathbf{3}$ was gradually red-shifted as the solvent polarity increased. That is the $\lambda_{\text {enI }}$ of 3 was 486 nin in non-polar solvent of $n$-hexane, and was progressively red-shifted to $510 \mathrm{~nm}$ in toluene, $54 \mathrm{Im}$ in dioxane, $566 \mathrm{~nm}$ in acetone, and eventually to $598 \mathrm{~nm}$ in polar solvent of methanol (Figure I). The fluorescence color changes of 3 in these solvents were distinctive and the blue color of the fluorescence 3 was dramatically changed to green, yellow, orange, and finally red in responding to the solvent polarities from $n$-hexane to methanol. In this case, the span of the spectral changes was relatively wide from $486 \mathrm{~nm}$ to $598 \mathrm{~nm}$ in visible region and the color changes were distinctive enough to be observable with naked eye. ${ }^{17}$

Along with the general solvatochromic fluorescence behavior of 3, a specific solvent effect has also been observed for the compound in various protic solvents. From the solvent dependent spectral changes, we have made a Lippert plot $^{18}$ between Stokes' shift $(\Delta v=$ the frequency shift (in $\mathrm{cm}^{-1}$ ) between absorption and emission) and orientation polarizability which is expressed as $\Delta f=(\varepsilon-1) \cdot(2 \varepsilon+1)-\left(n^{2}-\right.$ 1) $\left(2 n^{2}+1\right)$ (rigure 2). Stokes' shifts were approximately proportional to the orientation polarizability for the surveyed solvents except for the relatively large deviation of toluene and dioxane, and moderate scattering for protic solvents. ${ }^{18}$ The rationale for the significant deviations for the relatively nonpolar solvents of toluene and dioxane is not clear at the moment. However, the excess shifts for protic solvents could be explained by the specific interaction of the hydrogen bonding between the amino group of the fluorophore and the employed solvent molecules. These spectral behaviors suggest that the fluorescence characteristics of $\mathbf{3}$ are sensitive to both general solvent effects and specific solvent effect in protic solvent systems.

The effect of solvents on the fluorescence of $\mathbf{3}$ was further investigated systematically by using aqueous binary solutions

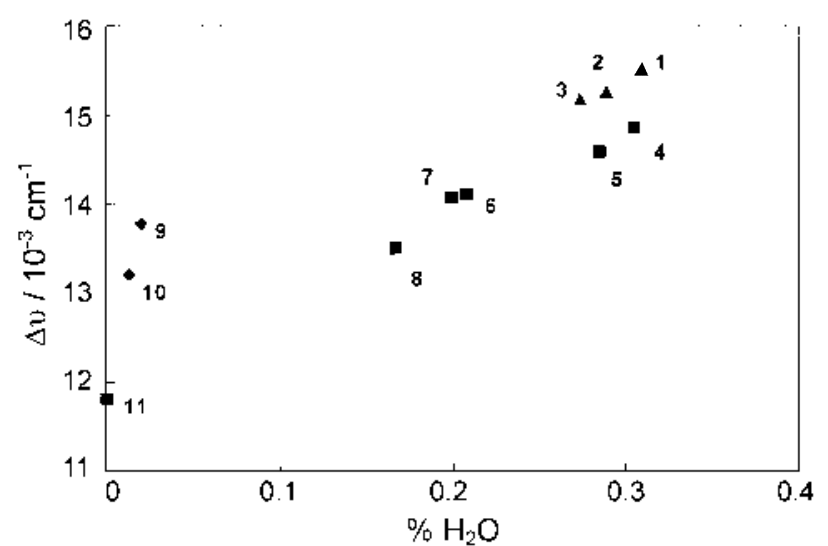

Figure 2. Itfeets of solvent polarity on the Stokes shitt in $\hat{\lambda}_{\text {ern }}$ of 3 . The numbers reler to the following solvents: I, methanol: 2 . sthanol: 3. n-propanol: 4. acctonitrilu: 5, acstone: 6 . THF: 7. cthyl acetate: 8. diethyl ether: 9. dioxane: 10. toluene; 11. hexane.

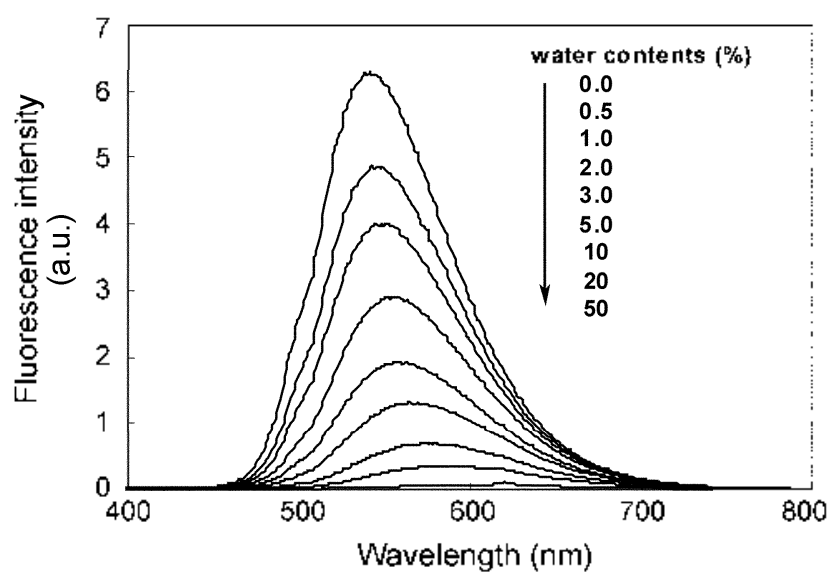

Figure 3. Fluorescence spectra of 3 as a function of water composition in aqueous 1.4 -dioxane. $[3]=2.0 \times 10^{-5} \mathrm{M}$. $\lambda_{\mathrm{x}}=310$ nm.

as medium. The compound $\mathbf{3}$ exhibited a strong fluorescence at $541 \mathrm{~nm}$ in pure 1.4-dioxane. However, as the percentage of water increases in aqueous dioxane solution, a gradual decrease in fluorescence intensity and a concomitant redshift in fluorescence maximum were observed (Figure 3). The red-shifts of fluorescence maximum and the decrease in fluorescence intensity were also visually recognized by the changes in fluorescence color of $\mathbf{3}$ from yellow to red with increases in water contents of solution. In this case, the absorption spectra of 3 were not affected significantly in aqueous organic solutions of varying water compositions.

The effects of water contents in binary aqueous solvent systems were further investigated in other water miscible aprotic solvents such as acetonitrile, acetone, and THF (Figure 4). Generally, adding small amount of water (up to $5 \%$ ) induced relatively large shifts in fluorescence maximum. After that, the changes became less significant. That is a typical of specific solvent effect and possibly due to the formation of strong hydrogen bonding between water and the amino group or nitrogen atoms of heterocyclic moieties of compound 3. This observation of sensitive spectral shifts 


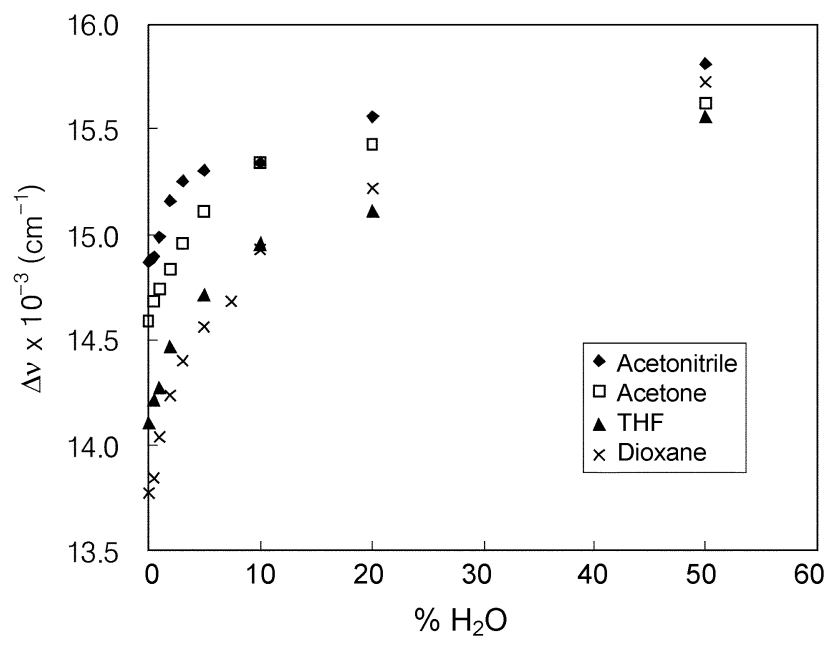

Figure 4. Effects of water composition in aprotic organic solvents on the tluorescence maximum of $3 .[3]=2.0 \times 10^{-5} \mathrm{~V} . \lambda_{t}=310$ $\mathrm{nm}$.

as a function of water composition suggests that the shift in $\lambda_{t+1}$ can be applied for the detection of water contents, ${ }^{19}$ especially in the range of up to $5 \%$ of water composition, in many aqueous organic solvent systems.

\section{Conclusions}

In conclusion, we have characterized a new sensitive fluorescent probe for solvent polarity of 8-aminoquinoline appended with benzothiazole function. The quinoline derivative exhibited a wide spectral shift in fluorescence emissions in visible region in response to the polarity of the medium. The compound also showed highly sensitive responses toward changes in water composition in aqueous solvent systems, which can be utilized as a new probe for the determination of water composition in aqueous binary solvent systems. The sensitive solvatochromic fluorescence behavior can also be used for the assessment of polarity characteristics in a variety of micro-environments in chemical and biological systems.

\section{Experimental Section}

General. All manipulations were carried out under an inert atmosphere. All solvents used for spectroscopic measurements were purchased from Aldrich Chemical Co. as 'anhydrous' or 'spectroscopic grade'. 2-Methyl-8-nitroquinoline and 2-aminothiophenol were purchased from Aldrich Chemical $\mathrm{Co} .{ }^{1} \mathrm{H}$ and ${ }^{13} \mathrm{C}$ NMK spectra were measured on a Varian Gemini-2000 spectrometer. HRMS spectra were obtained with a Micromass Autospec Mass Spectrometer. UV-Vis spectra were measured using a JASCO V-550 spectrophotometer.

Preparation of 8-nitro-2-quinolinecarboxaldehyde 1. A mixture of 2-methyl-8-nitroquinoline $(1.00 \mathrm{~g}, 5.3 \mathrm{mmol})$ and $\mathrm{SeO}_{2}(1.04 \mathrm{~g}, 9.4 \mathrm{mmol})$ in dioxane ${ }^{14}(30 \mathrm{~mL})$ was heated at $90^{\circ} \mathrm{C}$ for $2 \mathrm{~h}$. The reaction mixture was evaporated and the residue was dissolved in $\mathrm{CH}_{2} \mathrm{Cl}_{2}$, then filtered to remove undissolved solids. The filtrate was evaporated and redissolved in $\mathrm{MeOH}$. The solution was filtered and the filtrate was evaporated. Crystallization of the crude product from hexane gave pure compound $1(0.60 \mathrm{~g})$ in $56 \%$ yield. ' $\mathrm{H}$ NMR $(300 \mathrm{MHz}, \mathrm{CDCl}$ ) $\& 10.20(\mathrm{~s}, 1 \mathrm{H}), 8.55$ (d. $J=7.8$ $\mathrm{Hz}, 1 \mathrm{H}), 8.19-8.13(\mathrm{~m}, 3 \mathrm{H}), 7.79(\mathrm{t}, J=8.1 \mathrm{~Hz}, \mathrm{lH}) .{ }^{1 .} \mathrm{C}$ NMR (75 MHz, CDCl $): \delta 193.3,193.2,154.2,139.5$, 138.0, 132.1, 130.7. 128.1, 124.7, 119.2. HRMS (El): Calcd for $\mathrm{C}_{10} \mathrm{H}_{6} \mathrm{~N}_{2} \mathrm{O}_{3}\left(\mathrm{M}^{+}\right) 202.0378$. Found 203.0386 .

Preparation of 8-nitroquinoline benzothiazole 2 . To a solution of 1 (0.50 g. $2.5 \mathrm{mmol})$ in toluene ( $14 \mathrm{~mL}$ ) was added 2-aminothiophenol $(0.27 \mathrm{~mL}, 2.5 \mathrm{mmol})$ and acetic $\operatorname{acid}^{15}(0.14 \mathrm{ml}$.). The mixture was refluxed for $3 \mathrm{~h}$, cooled to room temperature and washed with dilute $\mathrm{HCl}$ and $\mathrm{NaHCO}_{3}$ $\left(10 \mathrm{ml}\right.$ ). The combined organic layer was dried over $\mathrm{Mg}_{2} \mathrm{SO}_{4}$ and evaporated. Crystallization from $\mathrm{MeOH}$ afforded pure compound $2(0.40 \mathrm{~g})$ in $52 \%$ yield. 'H NMR (300 MHz. CDCl $) \delta 8.64(\mathrm{~d}, J=8.7 \mathrm{H} 7,1 \mathrm{H}), 8.40(\mathrm{~d}, J=8.7 \mathrm{~Hz}, 1 \mathrm{H})$, $8.15-8.07(\mathrm{~m}, 3 \mathrm{H}) .7 .99(\mathrm{~d}, J=7.8 \mathrm{~Hz}, \mathrm{IH}) .7 .66(\mathrm{t} . J=7.8$ $\mathrm{Hz}, \mathrm{IH}), 7.54-7.46(\mathrm{~m}, 2 \mathrm{H}) .{ }^{13} \mathrm{C}$ NMR (75 MHz, CDCl $) \delta$ $167.0,154.6,153.7,148.3,139.5,137.3,132.2,129.8$, $126.7,126.6,126.4,125.0,124.3,122.5,120.2$. HRMS (El): Calcd for $\mathrm{C}_{16} \mathrm{H}_{19} \mathrm{~N}_{3} \mathrm{O}_{2} \mathrm{~S}\left(\mathrm{M}^{+}\right), 307,0415$. Found 307,0407 .

Preparation of 8-aminoquinoline benzothiazole 3. [o a suspension of $2(0.50 \mathrm{~g}, 1.63 \mathrm{mmol})$ in toluene $(33 \mathrm{~mL})$ and water $(3.8 \mathrm{~mL})$ at $85^{\circ} \mathrm{C}$ were added sodium hydrosulfite ${ }^{16}$ $(1.8 \mathrm{~g})$ and $\mathrm{NaHCO}_{3}(0.5 \mathrm{~g})$ in portion-wise over $2 \mathrm{~h}$. The reaction mixture was washed with $2 \% \mathrm{NaHCO}_{3}(10 \mathrm{ml}$.) and the separated organic phase was dried over $\mathrm{MgSO}_{4}$ and evaporated. Crystallization from $\mathrm{CH}_{2} \mathrm{Cl}_{2}$ yielded $3(0.35 \mathrm{~g}$, $78 \%)$ as a brown solid. 'H NMR (300 MHz, $\left.\mathrm{CDCl}_{3}\right) \delta 8.42$ $(\mathrm{d}, J=8.5 \mathrm{~Hz}, \mathrm{lH}), 8.19(\mathrm{~d}, J=8.5 \mathrm{~Hz}, \mathrm{IH}), 8.12(\mathrm{~d}, J=8.7$ $\mathrm{Hz}, \mathrm{lH}), 7.96(\mathrm{~d}, J=8.7 \mathrm{~Hz}, \mathrm{lH}) .7 .51(\mathrm{t}, J=7.4 \mathrm{~Hz}, \mathrm{lH})$, $7.42(\mathrm{t}, J=7.4 \mathrm{~Hz}, \mathrm{IH}), 7.37(\mathrm{t}, J=7.4 \mathrm{~Hz}, 1 \mathrm{H}), 7.18(\mathrm{~d}, J=$ $8.0 \mathrm{~Hz}, 1 \mathrm{H}), 6.96(\mathrm{~d}, J=7.4 \mathrm{~Hz}, \mathrm{IH}), 5.11(\mathrm{~s}, 2 \mathrm{H}) .{ }^{1.7} \mathrm{C}$ NMR $\left(75 \mathrm{MHz} \mathrm{CDCl}_{3}\right) \delta 169.9,154,4,148.3,144.1,137.6,136.9$, 136.3, 129.6, 128.8, 126.2. 125.7, 123.6, 121.8, 118.3, 115.9 . 110.6. HRMS (EI): Calcd for $\mathrm{C}_{16} \mathrm{H}_{1 \mid} \mathrm{N}_{3} \mathrm{~S}\left(\mathrm{M}^{+}\right) 277.0674$. Found 277.0655 .

Fluorescence titration experiments. Fluorescence measurements were performed using an Aminco-Bowman Series 2 Spectrometer. All the solvents used were spectroscopic grade. Incremental amounts of water were added to the stock solution of $3\left(2.0 \times 10^{-4} \mathrm{M}\right)$ in organic solvents by micropipette. After this, the solution was diluted with calculated amounts of water or organic solvents to make the required probe concentration as well as the solvent compositions.

Acknowledgement. This work was supported by ChungAng University (2004) and gratefully acknowledged.

\section{References}

1. (a) Chemosensurs of lon and holechle Recognition: Desvergne. J. P.: C.zarnik. A. W.. Eds.: Kluwer: [Dordrecht. 1997. (b) Fluowescent (hemosensors for tom and Holecule Recognition: Czarnik. $\Lambda$. W. 
Ed.: American Chemical Society: Washington. DC. 1993

2. Haugland. R. P. Hondbook of Flnorescent Probes and Research Products. 8th Ed: Molecular Probes: Eugene. 2001. See also http: www probes.com handbook:

3. Reichardt. C. Solvents and Solvent Effects in Organic Chemishr: 2nd ed.: VCH: Weinhem. 1988.

4. (a) Yam. V: Wong. K.: Zhu. N. J. Am. Chem. Soc. 2002. I2t. 6506. (b) Ercelen. S.: Klymchenko. A.: Demehenko. A. Anal. Chim. Acta 2002. 464. 273 , (c) Valle. J.: Catalan. J. Chemt. Phus. 2001, 270, 1 .

5. (a) Shin. E. I.: Lee, S. H. Bull Korean (Them. Soc. 2002. $23,1309$. (b) Shin. E. J. Bull. Korean Chem. Soc, 2004, 25,907.

6. Forlini. F.: Tritto. I.: Piemontesi. F. Afacromol Chent Phs 2000. 201.401 .

7. Cupane. A. L. M.: Fronticelli. C. J. Biol. Chent. 1997. 272. 26271 .

8. Rachofsky. E. L: Osman. R: Ross, I. B. Biochemishy 2001. to. 946.

9. Hisamoto. H.: Tohma. H.: Yamada. T.: Yamauchi. K.-I.: Siswanta. D.: Yoshioka. N.: Suzuki. K. Antal Chim. Acta 1998.373.271.

10. Tada. E. B.: Silva. P. L.: El Seoud. O. A. J. Phws. Org Chent.
2003. 16.691.

11. Peyritl. F. X.: Auillaume. Y. C. Anal. Chent 1999. 71. 2708.

12. (a) Pearce. D. A.: Totterand. N.: Carrico. I. S.: Imperiali. B. J. Ant. Chem. Soc, 2001, 123, 5160 . (b) Jiang. P.; Chen. L.: Lin, J.; Liu. Q: Ding. J.; Gao. X.: Guo. Z. Chem. Commm. 2002. 1424. (c) Bagatin. I; Souza, E.: Ito. A.; Toma, H. Inorg. Chem. Conmum. 2003. 6. 288. (d) Youk. J.-S.: Kim. Y. H.: Kim. E.-T.: Youn. N. J.: Chang. S.-K. Bull. Korean Chent Soc. 2004. 25. 869.

13. Youk. J.-S.: Kim. Y. H.: Moon. S. Y.: Choe. J. I.: Chang. S.-K Chem. Lett. 2004, 702 .

14. Hata. T; Uno. T. Bull. Chem. Soc. Jpn. 1972. 45, 477.

15. Iwamoto, K.: Araki. K.: Fujishima. H.: Shinkai. S. I. Chem. Soc. Perkin Trams. 1 1992. 1885.

16. Pratt. Y. T.: Drake. N. L. J. Ant Chent Soc. 1960. 82.1155

17. (a) Myaji. H.: Sato. W.: Sessler. T. Angew. Chem. In. Ed. 2000. 39. 1777. (b) Han, M. S.: Kim, D. H. Angew. Chem. Int. Ed. 2002. H. 3809 .

18. Lakowicz, J. R. Principles of Fluorescence Spectroscopy: 2nd ed. Kluwer: New York. 1999: p 196

19. Liu. W.: Wang. Y.: Jin. W.: Shen. G.: Yu. R. Anal Chint Acta 1999. 383.299 